\title{
Effects of preferred retinal locus placement on text navigation and development of advantageous trained retinal locus
}

\author{
Gale R. Watson, MEd, CLVT; ${ }^{*}$ Ronald A. Schuchard, PhD; ${ }^{1}$ William R. De l’Aune, PhD; ${ }^{2}$ Erica Watkins, BA $^{\mathbf{1}}$ \\ ${ }^{1}$ Blind Rehabilitation Service, Rehabilitation Research and Development Center of Excellence for Aging Veterans with \\ Vision Loss, Atlanta Department of Veterans Affairs Medical Center, Decatur, GA; ${ }^{2}$ Atlanta Research and Education \\ Foundation, Atlanta, GA
}

\begin{abstract}
Sixty readers were evaluated for visual function and text-navigation ability. The visual field and preferred retinal locus (PRL) were measured with a scanning laser ophthalmoscope (SLO). We found significant differences in text-navigation ability based on scotoma and PRL placement. Readers with a PRL to the left of or above a scotoma had significantly less textnavigation abilities. Readers with a PRL to the left of a scotoma tended to misread words with similar beginnings and omit the last word on a line. Readers with a PRL above a scotoma tended to skip a line or reread the same line twice. In a follow-up study, seven subjects with a nonadvantageous PRL quickly developed a trained retinal locus (TRL) during instruction with an SLO. Although the readers developed the TRL in about 15 minutes, they read slower with the TRL than the PRL. This TRL research provides promising pilot data.
\end{abstract}

Key words: low vision, macular scotoma, preferred retinal locus, reading, rehabilitation, scanning laser ophthalmoscope, text navigation, trained retinal locus, vision rehabilitation, visual impairment.

\section{INTRODUCTION}

The term "preferred retinal locus" (PRL) describes a retinal area that acts as a pseudofovea for visual tasks when a central macular scotoma affects visual performance. Individuals with macular disease who are unable to develop new skills with a PRL cannot optimally use lowvision devices or effectively use their remaining vision for reading [1]. The individual's visual system may not develop the best retinal area for reading with the PRL; for example, when reading, part of the word may be placed in the scotoma. Neither the individual nor the clinician may be aware of this misplacement except possibly through the clinician's observation of reading errors when the individual is reading aloud. Even individuals with a paracentral scotoma may have a scotoma that is next to the fovea and impairs reading. Low-vision rehabilitation effectively helps individuals with macular loss regain their reading abilities.

\section{Vision Function}

The prevalence of persons with low vision and macular scotomas is considerably larger than previously suspected. Fletcher et al. found a macular scotoma prevalence of

\footnotetext{
Abbreviations: ETDRS = Early Treatment Diabetic Retinopathy Study, logMAR = logarithm of minimum angle of resolution, MNREAD = Minnesota Low-Vision Reading (Acuity Charts), $\mathrm{OR}=$ odds ratio, $\mathrm{PRL}=$ preferred retinal locus, $\mathrm{SLO}=$ scanning laser ophthalmoscope, TRL $=$ trained retinal locus, VSRT = (Pepper) Visual Skills for Reading Test.

*Address all correspondence to Gale R. Watson, MEd, CLVT; Blind Rehabilitation Service, Rehabilitation Research and Development Center of Excellence for Aging Veterans with Vision Loss, Atlanta Department of Veterans Affairs Medical Center, 151-R, 1670 Clairmont Road, Decatur, GA 30033; 404-321-6111, ext 6789; fax: 404-7284837. Email: Gale.Watson@va.gov

DOI: 10.1682/JRRD.2005.07.0120
} 
about 83 percent in their typical low-vision rehabilitation service [2]. Less than half of these patients with low vision were diagnosed by their referring ophthalmologist or lowvision specialist as having macular scotomas.

Comprehensive rehabilitation can dramatically help persons with visual impairments achieve full lifestyles [3-4]. However, research has indicated that accurate, precise measurement of the scotoma area relative to the PRL for visual tasks may be important, if not critical, for visual performance tasks such as reading [5-9]. Macular scotomas also impair visual functions such as contrast sensitivity [10], contrast discrimination [11], stereoscopic depth perception [12], and fixation precision/stability [5,13].

Even when persons are aware of a scotoma (they see a blurry, hazy gray area), they are seldom aware of the true extent of the scotoma [14]. Persons typically describe new scotomas resulting from laser treatments as "large black spots" or "boulders," but over a few months, these spots fade and can no longer be localized without perimetric testing. In an eye with a central scotoma affecting the entire fovea, one or more eccentric PRLs naturally and reliably develop [5-7,15-17]. A shift of the oculocentric reference from the fovea to an eccentric PRL is possible in persons with bilateral macular disease [11,16].

Fletcher et al. used the scanning laser ophthalmoscope (SLO) to study the characteristics of macular scotomas in 742 eyes [2]. The retinal locations of fixation, foveal PRL or eccentric PRL, were recorded and graded. Dense scotomas were mapped with a 12 arcminute square target with a 50,000 Td retinal illuminance. Relative scotomas were also mapped with the use of targets at the retinal illuminance level that was determined to represent the threshold sensitivity of the fovea or eccentric PRL. With this testing method, fixation could be monitored. Even in persons with very unsteady fixation, macular scotomas were identified in relationship to the anatomy of the macula. The size, location, and density of scotomas cannot be inferred consistently from the ophthalmoscopic appearance of the macula. Figure 1 depicts an SLO retinal map.

In Fletcher et al.'s study [2], 83 percent (616/742) of eyes had dense scotomatous areas present in the central visual field, 14 percent (101/742) had scotomas of less than $5^{\circ}$ in diameter, and 69 percent $(515 / 742)$ had scotomas of greater than $5^{\circ}$ in diameter. Scotoma shape varied widely, from round scotomas centered on a nonfunction- ing fovea to ring scotomas surrounding a functioning fovea to highly complex amoeboid shapes. The PRL (for fixation) was frequently near a dense scotoma. The relationship of the PRL to surrounding dense scotomas in the visual field was categorized by how many of the four borders (superior, inferior, right, and left) around the PRL were dense scotomas. (Note: a visual field dense scotoma to the left of the PRL corresponds to an area of nonfunctioning retina anatomically to the right of the PRL.) The total number of dense-scotoma borders around the PRL were (1) no borders: 22 percent, (2) one border: 46 percent, (3) two borders: 14 percent, (4) three borders: 7 percent, and (5) four borders (ring scotoma): 11 percent.

Fletcher and Schuchard have developed and used a uniform PRL scoring system using an SLO to determine measurable qualities of the PRL [18]. The SLO directly determines the retinal location of visual stimuli with respect to retinal image characteristics. Their retinallocation scoring mechanism includes PRL size, fixation ability, saccade ability, and pursuit ability. PRL size is recorded in degrees. PRL fixation, saccade, and pursuit abilities are scored from 0 to 4; 0 indicates no ability and

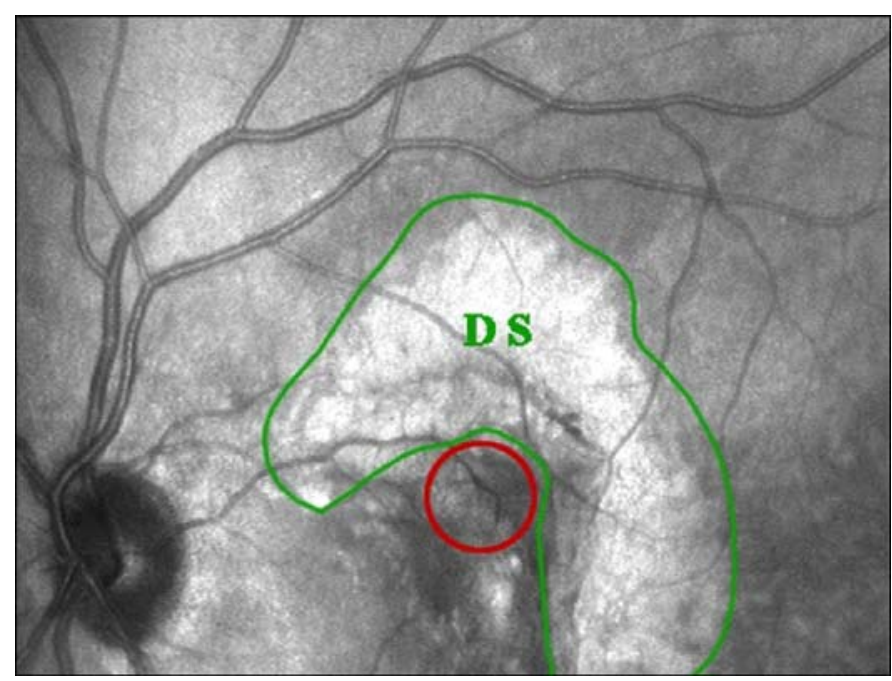

Figure 1.

Scanning laser ophthalmoscope (SLO) retinal map of scotoma shape and size (outlined in green) and documented position and size of nonfoveal preferred retinal locus (PRL) (outlined in red). Green outline of scotoma border is artistic rendering of dense scotoma (DS). Green area encompasses nonseeing retinal points as designated by manual hybrid perimetry with fixation monitoring in SLO. Note: anatomic area of nonfunctioning retina anatomically to right of PRL corresponds to visual field dense scotoma to left of PRL. 
4 indicates abilities that approximate those of a person using foveal vision.

\section{Reading with Preferred Retinal Locus}

Programs that teach the visual skills used in reading have been developed and widely used [19-21]. Previous research has shown that training individuals with macular degeneration in visual skills and use of low-vision devices effectively increases reading accuracy [22-23], rate [24-25], and comprehension [26-27].

Two oral reading assessments, the Pepper Visual Skills for Reading Test (VSRT) and the Minnesota LowVision Reading (MNREAD) Acuity Charts, have been developed and standardized for persons with low vision and are commonly used research measures. These assessments were developed for quick evaluation of reading ability, since persons with low vision are likely to read more slowly and fatigue more quickly than persons without visual impairments.

The Pepper VSRT is a highly reliable assessment of text-navigation ability [28] and is used in low-vision clinics for diagnosis and remediation of reading problems in persons with macular degeneration [23,29]. The test can be administered in approximately 10 minutes and can diagnose specific reading errors of persons with macular scotomas. Rate and accuracy scores and diagnoses of specific errors can be derived. This test was highly valid when compared with the Gray Oral Reading Tests, a graded reading evaluation of continuous text [30]. Classified error codes were developed for providing an accuracy score. Errors include omissions, insertions, misidentifications, connecting words, separating words, and skipping lines.

The MNREAD Acuity Charts simply and quickly estimate reading acuity, maximum reading rate, and critical print size (smallest print size at which fluent reading can be maintained) of persons with low vision [31]. Unlike the Pepper VSRT, which evaluates visual skills in reading, the MNREAD Acuity Charts assess reading acuity and rate in a controlled manner and derive critical print size for most fluent reading. The MNREAD Acuity Charts have high test-retest reliability and are highly correlated with silent reading ability (as measured by comprehension).

Fletcher et al. documented the characteristics of macular scotomas relative to the PRL by relating SLO macular perimetry to reading performance [1]. The PRL ability (fixation stability, pursuit ability, and saccadic ability) was rated with the 0 to 4 scoring system just described [18]. This SLO test, a test of visual acuity
(Early Treatment Diabetic Retinopathy Study [ETDRS] chart), and the MNREAD Acuity Charts [31] were administered to 40 patients during the initial visit before rehabilitation intervention. The MNREAD Acuity Charts were administered as recommended. As in a previous study [9], Snellen acuity accounted for only 19 percent of the variability in reading rate, a scotoma above and/or below the PRL accounted for only 12 percent, and fixation stability accounted for 27 percent. However, other studied clinical variables had much stronger relationships to reading rate than previously studied parameters. Saccadic ability accounted for 38 percent of the variability in reading rate, pursuit ability accounted for 37 percent, and a scotoma to the right and/or left of the PRL accounted for 40 percent. Subjects with scotomas to both the right and left of the PRL or subjects with scotomas only to the right had significantly reduced reading rates compared with subjects with scotomas to the left or no scotomas on either side of the PRL.

\section{Trained Retinal Locus}

Nilsson reported that, since the 1970s, a low-vision service in Sweden has been instructing patients in the use of a trained retinal locus (TRL) in a retinal area that is "more advantageous to reading," defined as above or below an absolute central scotoma as opposed to the left or right of the scotoma [25]. In Nilsson et al.'s feasibility study, they trained a retinal locus in a scotomatous eye; each subject's other eye was unimpaired [32]. Their results showed that subjects who did not develop a PRL in the scotomatous eye (because they had one unimpaired eye) developed a TRL in the scotomatous eye and had significantly improved reading rates with the scotomatous eye following training.

Nilsson et al. further reported on 20 persons with age-related macular degeneration and central scotomas in both eyes who were trained to develop a TRL [33]. In 18 subjects, the study eye was the lesser-seeing eye, since the researchers wanted to avoid using subjects who had already been trained to use eccentric viewing methods. For the remaining two subjects, one had equal acuity in both eyes and one had a rapidly progressing lesion that prevented training of the lesser-seeing eye. None of their subjects had been exposed to rehabilitation, had access to magnification devices, or had been currently reading by using their vision. Eleven subjects had a PRL to the left of the lesion, six had a PRL to the upper-left of the lesion, two had a PRL to the lower-left of the lesion, and one had 
a PRL to the right of the lesion. The subjects were trained via SLO. Subjects were taught to look at a letter in the center of crossed lines; the letter was slowly moved so that the subject saw the letter projected in a "trained retinal locus" area, while the crossed lines remained in the scotoma. The subject was told to continue looking at the letter; the crossed lines remained as a reference point and assured that the subject understood how to continue viewing with the TRL.

Nilsson et al. reported that they could use the SLO to constantly check the subject's fixation and correct it if the subject lost the fixation from the trained area [33]. After training with the SLO, subjects were taught to use the TRL with high-plus magnifying spectacles [33]. Exercises with similar fixation lines were used [19]. Rather than use fixation and saccadic eye movements, the subjects were taught to scroll printed reading exercises so that the words moved into the TRL field of view.

The authors reported that 18 of the 20 subjects developed a TRL [33]. Of the remaining two subjects, one was unable to use a TRL after 5 hours of training and one refused to use the magnifying spectacles. Of the 18 subjects who developed a TRL, 12 were trained to use a TRL below the visual-field scotoma and 6 were taught to use a TRL above the visual-field scotoma. Subjects received an average of 5.4 hours of training, with 1 week of homework between each training session. Mean reading rate prior to training was 9.7 words/minute; after training, mean reading rate was 68.3 words/minute. The authors concluded that their subjects were able to be trained to use a TRL and following rehabilitation, study eyes showed significantly increased reading rates with the TRL. However, the authors did not train the subjects' naturally occurring PRL, so we do not know what ability the study eyes might have acquired had their PRL been trained. In earlier studies [25], these researchers achieved dramatic and similar increases in reading rates (from 0 to 75.5 words/minute) through training for approximately the same rehabilitation time period but without direct monitoring of eye movements. One must question, then, whether training is the most important aspect of reading rate improvement, regardless of whether the reader uses a PRL or TRL.

We do not know what ability Nilsson et al.'s subjects might have gained if their better-seeing eyes had been trained. The better-seeing eye is generally chosen for rehabilitation in low-vision clinics unless a patient can read with a binocular low-vision device, such as a closedcircuit television system or a hand/stand magnifier.

Nilsson et al. also concluded that a PRL to the left or right of a scotoma was not advantageous and a PRL above or below a scotoma was better for maximal reading ability [33]. Unfortunately, these conclusions are based on clinical heuristics and laboratory research on subjects without visual impairments who were provided with artificial scotomas [34-35]. In a study of readers with low vision with naturally occurring central scotomas, Fletcher et al. did not find an advantage of any particular PRL-scotoma position for reading rate [1].

Our study investigated whether PRL and scotoma placement were related to text-navigation ability in subjects with low vision. We also investigated whether a TRL could be developed in the better-seeing eyes of subjects with low vision who were long-term PRL users.

\section{EXPERIMENT 1}

\section{Methods}

We recruited 60 subjects who had visual impairments due to macular diseases (absolute scotoma in the visual field as measured by the SLO perimetry), 20/800 or better acuity in the better-seeing eye, and interest in reading with low-vision devices. We obtained the subjects' informed consent using the procedures required by the Emory University Human Investigations Committee.

Following informed consent, subjects were evaluated without low-vision devices by the following procedures:

1. ETDRS Distance Visual Acuity Charts: Distance acuity.

2. MNREAD Acuity Charts: Reading acuity, reading rate, and critical print size.

3. Pepper VSRT (with low-vision devices): Text navigation ability, reading accuracy, and reading rate.

4. SLO testing: Macular perimetry as described by Sunness et al. [36] and PRL characteristics, including fixation stability, as described by Fletcher and Schuchard [18]. The confocal SLO with graphics capabilities allows an examiner to directly determine the retinal location of visual stimuli on the retinal image in real time. The SLO with graphics capabilities continuously obtains retinal images with a nearly invisible infrared laser $(780 \mathrm{~nm})$ and scans graphics (e.g., lines, letters, and words) on the retina with a modulated visible redlight laser $(633 \mathrm{~nm})$. Thus, the subject observes the stimuli, which the examiner sees directly on the 
subject's retina. The retinal illuminance of the stimuli is adjustable by 256 steps within the visible red-light laser range (50-50,000 Td). The SLO provides a $32^{\circ} \times 22^{\circ}$ image of the retina with a minimum resolution of approximately 4 arcminutes for measurement of the retinal areas and positioning of targets. Macular scotomas can be mapped on the SLO with kinetic, static, or hybrid testing techniques.

5. Binocular perception test: Evaluation of dominant PRL. A computer system displayed stereo pairs sequentially on a monitor at $120 \mathrm{~Hz}$. The electronic eyewear, liquid crystal shutters synchronized with the monitor, determined which eye saw each frame of the stereo pair. When the left image was on the video screen, for example, the left shutter opened while the right shutter closed. The subject was told to fixate a $1^{\circ}$ star (seen as a cross by the right eye, an $\mathrm{X}$ by the left eye, and a star binocularly), then report which target was seen. If the subject reported a cross or an X, then he or she was not seeing the visual information from the PRL/fovea of both eyes during binocular viewing.

\section{Results}

Table 1 shows subjects' ages; scores on vision function, reading, and visual acuity measures; and PRL performance.

We determined fixation size for the PRL by measuring fixation eye movements for 20 seconds; the diameter that we recorded encompassed the area of fixation eye movements [18]. We reported PRL performance using

Table 1.

Ages and scores on vision function and reading measures for 60 subjects with absolute scotoma in visual field in Experiment 1.

\begin{tabular}{lcc}
\hline \multicolumn{1}{c}{ Measure } & Mean \pm SD & Range \\
\hline Age (yr) & $74.5 \pm 10.6$ & 23 \\
Acuity (logMAR) & $0.8 \pm 0.3$ & $0.1-1.5$ \\
PRL Size ( ${ }^{\circ}$ fixation) & $3.9 \pm 2.1$ & $1.5-10$ \\
Fixation Ability Score & $3.0 \pm 0.7$ & $0-4$ \\
Pursuit Score & $2.5 \pm 0.7$ & $0-4$ \\
Saccade Score & $2.3 \pm 0.9$ & $0-4$ \\
MNREAD Critical Print Size (logMAR) & $1.1 \pm 0.4$ & $0.2-1.6$ \\
MNREAD Acuity (logMAR) & $0.9 \pm 0.4$ & $0.1-1.7$ \\
MNREAD Rate (words/min) & $78.1 \pm 52.4$ & $4-210$ \\
Pepper VSRT Rate (words/min) & $29.0 \pm 17.6$ & $3.5-81.8$ \\
Pepper VSRT Accuracy (\%) & $83.8 \pm 19.4$ & $20.8-99.3$ \\
\hline logMAR = logarithm of minimum angle of resolution, MNREAD = Minnesota \\
Low-Vision Reading (Acuity Charts), PRL = preferred retinal locus, SD = \\
standard deviation, VSRT = Visual Skills for Reading Test. \\
\hline \hline
\end{tabular}

the previously described method of rating from 0 to 4 the subject's use of the PRL in the SLO for fixation, pursuit, and saccade abilities [18]; 0 indicated no ability and 4 indicated that the subject's off-foveal PRL ability was similar to that for a foveal PRL.

Rate, accuracy, and error scores on the Pepper VSRT were recorded and matched to the PRL recorded on the SLO. We coded text-navigation errors on the Pepper VSRT as left directional errors, right directional errors, or below directional errors. Left directional errors were missing or confusing the beginning of a word or missing the first word on a line. Right directional errors were missing or confusing the ending of a word or missing the last word on a line. Below directional errors were skipping a line or reading the same line twice. In this article, we report results for text-navigation errors only; other results will be published later.

We scored scotomas by placing a matrix over the SLO field plot. The matrix was a transparency with concentric circles, a center fixation dot, and eight radial lines from the center fixation dot. The fixation dot was centered over the PRL; each of the radials was examined. By using this overlay, we determined the presence or absence of a dense scotoma on each radial. Scotoma configuration may have included several radials. Figure 2 depictions the matrix transparency over an SLO map.

For this analysis, we used dense scotomas in the eye with the dominant PRL; if no dominant PRL existed, we used dense scotomas in the subject's preferred eye.

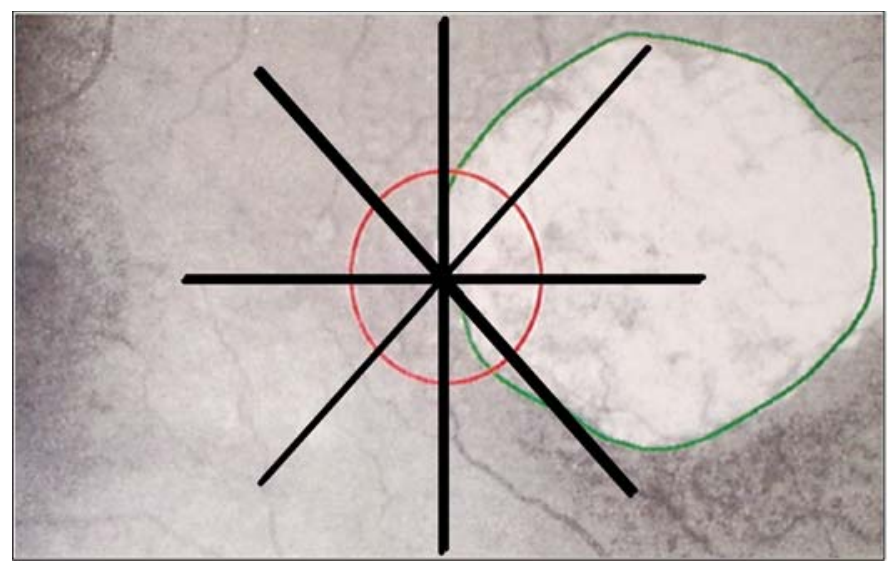

Figure 2.

Transparency overlay for scoring scotomas. Matrix was transparency with concentric circles, center fixation dot (outlined in red), and eight radial lines from center fixation dot. Scotoma is outlined in green. 
We coded subjects' reading errors on the Pepper VSRT as specific directional errors; "right” errors were mistaking the ending of a word or omitting the last word on a line, "left" errors were mistaking the beginning of a word or omitting the first word on a line, and "below" errors were skipping or rereading a line.

We performed a simple analysis of the presence or absence of directional reading errors (right, left, below) from the Pepper VSRT and the presence or absence of scotomas in each radial from the PRL. In each case, we constructed a fourfold table and performed a chi-square analysis. A total of 24 fourfold tables were constructed and analyzed. For each table, we evaluated the significance of the resultant chi-square value, and if it was statistically significant, we computed and reported an odds ratio (OR). We obtained the following results:

- A dense scotoma to the right of the PRL (radial 3) was associated with more right errors $\left(\chi^{2}=4.1, p=\right.$ $0.05)$. The OR indicated that a scotoma in this radial was associated with 2.033 times the likelihood of right errors. A dense scotoma to the left of the PRL (radial 7) was associated with one-third fewer right errors (OR $\left.=0.348 ; \chi^{2}=3.9, p=0.048\right)$.

- Left errors were not associated with any particular PRL configuration.

- A dense scotoma below the PRL (radial 1) was associated with below errors $\left(\chi^{2}=4.2, p=0.04\right)$. The OR indicated that a scotoma in this radial was associated with 3.368 times the likelihood of below errors. A dense scotoma below and to the right of the PRL (radial 2) was also associated with below errors $\left(\chi^{2}=\right.$ 5.9, $p=0.015)$. The OR indicated that a scotoma on this radial was associated with 4.474 times the likelihood of below errors.

\section{EXPERIMENT 2}

\section{Methods}

In the second experiment, we recruited subjects whose naturally occurring PRL was to the left of their scotoma and trained them to develop a TRL that was below their scotoma. We chose the PRL location based on our and others' research that found this location to be disadvantageous for reading, and we chose the TRL location based on our and others' research that found this location to be advantageous for reading. To locate subjects whose PRL was to the left of their scotoma, we screened the records of the 60 subjects from Experiment 1 for whom we already had documented SLO visual fields. Of these 60 subjects, 13 fit our criterion but 3 had either moved or were ill. The remaining 10 potential subjects provided informed consent according to the requirements of the Emory University Human Investigations Committee and were pretested for acuity and central visual-field perimetry via SLO. Three subjects had changed PRL locations (two had continued macular loss and one deliberately changed his PRL, as explained in the "Discussion" section). This resulted in seven subjects who agreed to participate. Because of the very small sample size, this experiment was exploratory.

We administered the retinal locus characteristics and ability scales using the SLO [18], the Pepper VSRT $[28,30]$, and the MNREAD Acuity Charts [31]. We instructed subjects in development of a TRL below the scotoma and in use of this TRL for reading words presented on the SLO. Following this instruction, we readministered all tests.

\section{Results}

We could not completely ascertain whether subjects were reading with the PRL or TRL when they were viewing the reading charts in posttesting; however, subjects verbalized their understanding and monitored their own eye movements after training. They demonstrated appropriate eccentric viewing techniques when asked to view the experimenter's face and other near targets, showing that they understood and could use the TRL, rather than the PRL, in posttesting.

The average age of the subjects was 75.7 , with a range from 68 to 82. The average subject acuity was right eye = 1.0 logarithm of minimum angle of resolution (logMAR) (range 0.64-1.26), left eye $=0.98$ logMAR (range 0.481.52 ), both eyes $=0.91$ logMAR (range 0.64-1.12), and dominant PRL = 0.95 logMAR (range 0.64-1.18).

In our SLO protocol, we used a fixation target (cross) in the PRL as a "tag" and another target (letter) for secondary fixation with the TRL. We gave the subject verbal feedback while viewing his or her performance in the SLO to assist development of the TRL. The subject was told to "look at" the cross in the PRL and "notice" the letter in the TRL. We used this method to help the subject understand the difference between the PRL and TRL and avoid a situation in which the subject was tempted in the early training stage to "look" with the PRL at the TRL target. Targets in the TRL were initially single letters and 
then two-letter words, three-letter words, etc. Figure 3 depicts the SLO map during TRL training.

When the subject consistently fixated, used the TRL for eye movements, and read several successive words with the TRL, we extinguished the PRL fixation target (cross). The TRL was subsequently used for further eye

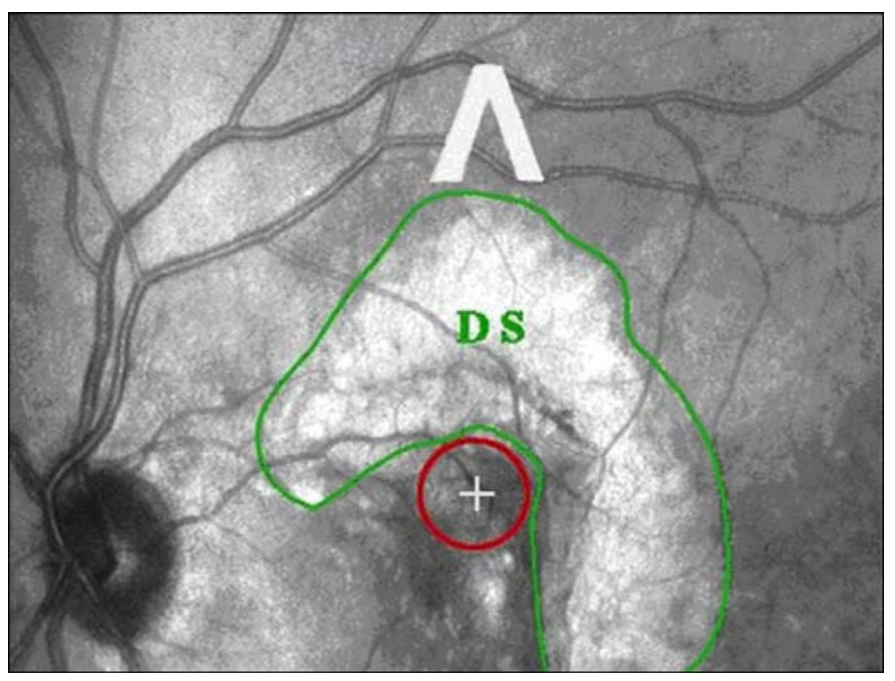

Figure 3.

Scanning laser ophthalmoscope (SLO) image during trained retinal locus (TRL) instruction of subject with central dense scotoma (DS) (outlined in green). Subject looked at cross $(+)$ with preferred retinal locus (PRL) (outlined in red). Subject was asked to look at + and notice V shown in TRL. V and + are superimposed on SLO image. Once subject understood and complied with TRL training, + was extinguished. SLO image vertically inverted as would be seen by experimenter. Subject would see V below scotoma, while experimenter would see $\mathrm{V}$ above scotoma. movement and reading instruction. We gave the subjects a short break, then had them read again in the SLO. All subjects were able to read with the TRL after the break; none reverted to the PRL to read words in the SLO.

Table 2 provides the subjects' PRL and TRL characteristics. All subjects developed a TRL after an approximately 15-minute training session. This training session with the SLO resulted in a TRL that closely matched the PRL in size and in fixation, saccade, and pursuit abilities. The TRL and PRL abilities did not significantly differ.

Subjects read significantly slower and with less textnavigation ability with the TRL than the PRL. However, considering that the training session was short, provided exclusively in the SLO, and did not include practice following the SLO intervention, subject performance was surprisingly responsive.

\section{DISCUSSION}

Experiment 1 showed very strong associations between scotoma placement and reading errors on the Pepper VSRT. We found that a scotoma to the right of the PRL was related to reading errors on the right (missing the end of words or the last word on the line of print). A scotoma below the PRL was strongly related to reading performance (both errors of skipping or rereading a line of print and slower reading rate), a finding that has never been reported in the literature. We expected to find that scotoma to the left of the PRL would be related to reading errors on the left (missing or confusing the beginning of a

Table 2.

Preferred retinal locus (PRL) and trained retinal locus (TRL) characteristics for seven subjects in Experiment 2.

\begin{tabular}{|c|c|c|c|c|c|c|}
\hline \multirow{2}{*}{ Characteristic } & \multicolumn{3}{|c|}{ PRL } & \multicolumn{3}{|c|}{ TRL } \\
\hline & Mean & Minimum & Maximum & Mean & Minimum & Maximum \\
\hline Fixation Ability Score & 3 & 3 & 3 & 3 & 3 & 3 \\
\hline Saccade Ability Score & 2.4 & 2.0 & 3.0 & 2.0 & 1.0 & 3.0 \\
\hline Pursuit Ability Score & 3.0 & 3.0 & 3.0 & 2.2 & 1.0 & 3.0 \\
\hline \multicolumn{7}{|l|}{ Reading Ability } \\
\hline MNREAD Acuity (logMAR) & 1.14 & 0.71 & 1.42 & 1.34 & 1.02 & 1.66 \\
\hline Critical Print Size (logMAR) & 1.33 & 0.80 & 1.60 & 1.45 & 1.30 & 1.60 \\
\hline Pepper VSRT Rate (words/min) & 27.1 & 12.3 & 41.2 & 17.1 & 11.3 & 29.6 \\
\hline Pepper VSRT Accuracy (\%) & 94.4 & 87.9 & 99.3 & 72.6 & 54.6 & 94.7 \\
\hline
\end{tabular}


word or missing the first word on a line), but this proved not to be the case.

Other low-vision clinicians and clinical researchers have suggested that a PRL above or below a scotoma is the most suitable PRL for reading because the scotoma does not interfere with scanning across the line of print $[19,25,33,37]$. Our data show that a PRL above the scotoma is strongly associated with rereading lines or skipping lines, which severely disrupts the reading process. Our findings of the deleterious effects of a PRL above a central scotoma make intuitive sense. Because we read English from left to right and top to bottom, a scotoma in this position always obscures that which is below fixation. Because most languages are read from the top of a page to the bottom, even non-English readers with such a scotoma may have this difficulty.

Other low-vision clinicians and researchers have also stated that a PRL to the right of a scotoma is a disadvantageous reading position because a scotoma in this position would ostensibly cause errors in scanning a line of print $[19,25,33,37]$. Although problematic in the laboratory for readers without visual impairments using artificial scotomas, our research does not show that readers with macular scotomas are disadvantaged. Our readers with scotomas in this position actually showed an advantage in reading the ends of words and the last word on a line correctly. A PRL to the right of the scotoma may provide suitable reading ability.

The results of Experiment 1 challenge former thinking about the relationship between scotoma placement and reading performance. Our data suggest that the position of the PRL relative to the scotoma may be important for readers with macular loss but not as important as was previously thought. Prevailing clinical heuristics that a scotoma to the right of the PRL is deleterious and a scotoma above the PRL is advantageous appear to have been validated. However, a scotoma below the PRL may impair performance more than previously thought and a scotoma to the left of the PRL may be more benign. In clinics providing PRL training, low-vision clinicians can use this information to better understand their patients' reading performance.

Another result of our research is that error scores on the Pepper VSRT are useful for determining the effect of PRL placement on text navigation. The error scores as coded and used in this research may be a quick, expedient proxy for determining PRL position in the absence of an SLO. A fixation target in a fundus camera [32] or visuoscope for determining retinal fixation position can provide this information as well and has been used successfully as an SLO proxy.

Although only a small number of subjects who were screened qualified for Experiment 2, all subjects in this experiment were able to develop a TRL in their betterseeing eye with a well-developed PRL after approximately 15 minutes of SLO training. This SLO training session resulted in a TRL that closely matched the PRL in size and in fixation, saccade, and pursuit abilities. We did not measure the distance of the PRL and TRL from the fovea, so we do not know whether fixation stability was similar because of this reason. The fixation scoring scale may be a relatively coarse measure, and more precise measures might have shown more differences in fixation stability, pursuits, and saccades.

Subjects read significantly slower and with less textnavigation ability with the TRL than the PRL. However, considering that the training session was very short, provided exclusively in the SLO environment, and did not include practice following the SLO intervention, subject performance was surprisingly good. These subjects were regular readers with a longstanding PRL; therefore, their uniform ability to develop and use a TRL in the betterseeing eye after a 15-minute SLO training intervention is very encouraging. The results, while suggestive, were not subjected to inferential statistical testing and must be interpreted in terms of their exploratory nature. However, we conclude, as do other researchers, that TRL development is an area that deserves more research and clinical attention.

Our subjects had long-standing macular loss (duration of at least 1 year) and were experienced low-vision device users. They had been subjects in various experiments at our center and volunteered eagerly for various reasons: to gain more information about their visual impairments, to enjoy a novel experience, to understand whether something new might assist them in daily life, etc. Some personality mechanism or other psychosocial characteristic may have motivated these low-vision readers to become research subjects and therefore respond willingly and easily to our TRL training.

On the other hand, this is the first report of training a TRL in the better-seeing eye of patients with macular loss who were using their better-seeing eye with low-vision devices for reading. These readers developed a TRL with relative ease and speed. Whether it is possible for the general clinical population in a low vision service to do so 
and find the TRL as useful as a PRL remains to be seen. We do not know how long the effect of this short-term TRL development lasted because we did not follow the subjects.

One subject screened for Experiment 2 reported that he had deliberately taught himself to use a TRL. Whereas he had earlier demonstrated a PRL to the left of the scotoma, at the recall visit, he demonstrated a retinal locus below the scotoma. When the experimenter remarked on this change, the subject stated that he had requested and received his Pepper VSRT results from Experiment 1, which demonstrated right directional errors. Upon returning home, he taught himself to change his fixation and found that reading was easier. Although he was dismissed as a subject, the results of his enterprising self-training and our study are in agreement and are encouraging.

\section{CONCLUSIONS}

Contrary to clinical heuristics, we found that the textnavigation performance of our readers with macular degeneration who had a PRL to the right of a scotoma did not suffer unduly. We further found that text-navigation of readers with a PRL above a scotoma was more problematic than previously believed. This research questions some of the commonly used assessment and training techniques developed for this population. Although clinical heuristics are prevalent in medicine and rehabilitation as quick "rules-of-thumb," for practice, they must be carefully evaluated.

Our subset of readers was able to quickly and reliably develop a TRL in a position that was advantageous for scanning text. Promising lines of future research are to discover whether other advantageous TRL positions (such as to the right of the scotoma) exist, whether a longer training and practice session would improve performance, and whether persons with macular loss can be taught this technique without use of an SLO.

\section{ACKNOWLEDGMENTS}

This material was based on work supported by the Department of Veterans Affairs, Rehabilitation Research and Development Service (VA RR\&D), grant C849-RA (Gale R. Watson); and the Atlanta VA RR\&D Center of
Excellence for Aging Veterans with Vision Loss (Gale R. Watson).

The authors have declared that no competing interests exist.

\section{REFERENCES}

1. Fletcher DC, Schuchard RA, Watson GR. Relative locations of macular scotomas near the PRL: Effect on low vision reading. J Rehabil Res Dev. 1999;36(4):56-64. [PMID: 10678458]

2. Fletcher DC, Schuchard RA, Livingstone CL, Crane WG, $\mathrm{Hu}$ SY. Scanning laser ophthalmoscope (SLO) macular perimetry and applications for low vision rehabilitation clinicians. Ophthalmol Clin N Am. 1994;7:257-65.

3. Maino JH, Carty RE. Part II. VICTORS: A model for the provision of low vision services to the partially sighted veteran. J Am Optom Assoc. 1983;54(11):991-93. [PMID: 6643902]

4. Watson GR, De l'Aune WR, Stelmack JA, Maino JH, Long S. National survey of the impact of low vision device use among veterans. Optom Vis Sci. 1997;74(5):249-59. [PMID: 9219282]

5. Timberlake GT, Mainster MA, Peli E, Augliere RA, Essock EA, Arend LE. Reading with a macular scotoma. I. Retinal location of scotoma and fixation area. Invest Ophthalmol Vis Sci. 1986;27(7):1137-47. [PMID: 3721792$]$

6. Timberlake GT, Peli E, Essock EA, Augliere RA. Reading with a macular scotoma. II. Retinal locus for scanning text. Invest Ophthalmol Vis Sci. 1987;28(8):1268-74. [PMID: 3610545$]$

7. Cummings RW, Whittaker SG, Watson GR, Budd JM. Scanning characters and reading with a central scotoma. Am J Optom Physiol Opt. 1985;62(12):833-43. [PMID: 4083327]

8. Legge GE, Rubin GS, Pelli DG, Schleske MM. Psychophysics of reading-II. Low vision. Vision Res. 1985; 25(2):253-66. [PMID: 4013092]

9. Legge GE, Ross JA, Isenberg LM, LaMay JM. Psychophysics of reading. Clinical predictors of low-vision reading speed. Invest Ophthalmol Vis Sci. 1992;33(3):677-87. [PMID: 1544792]

10. Mitra S. Spatial contrast sensitivity in macular disorder. Doc Ophthalmol. 1985;59(3):247-67. [PMID: 4006670]

11. Schuchard RA, Raasch TW. Retinal locus for fixation: Pericentral fixation targets. Clin Vis Sci. 1992;7:511-620.

12. Raasch TW. Method for assessing stereopsis and positional sensitivity in normally-sighted and low vision observers. Opt Soc Am Tech Dig Ser. 1991;1:109-12. 
13. Schuchard RA, Fletcher DC, Maino JH. A scanning laser ophthalmoscope low vision rehabilitation system. Eye Clin Vis Care. 1994;6:101-7.

14. Schuchard RA. Validity and interpretation of Amsler grid reports. Arch Ophthalmol. 1993;111(6):776-80. [PMID: 8512478]

15. Whittaker SG, Budd JM, Cummings RW. Eccentric fixation with macular scotoma. Invest Ophthalmol Vis Sci. 1988;29(2):268-78. [PMID: 3338884]

16. White JM, Bedell HE. The oculomotor reference in humans with bilateral macular disease. Invest Ophthalmol Vis Sci. 1990;31(6):1149-61. [PMID: 2354915]

17. Schuchard RA, Fletcher DC. Preferred retinal locus. A review with applications in low vision rehabilitation. Ophthalmol Clin N Am. 1994;7:243-56.

18. Fletcher DC, Schuchard RA. Preferred retinal loci relationship to macular scotomas in a low-vision population. Ophthalmology. 1997;104(4):632-38. [PMID: 9111255]

19. Bäckman O, Inde K. Low vision training. Malmö (Sweden): LiberHermods; 1979.

20. Watson GR, Berg RV. Near training techniques. In: Jose RT, editor. Understanding low vision. New York (NY): American Foundation for the Blind; 1983. p. 317-62.

21. Wright VW, Watson GR. Learn to use your vision for reading workbook. Lilburn (GA): Bear Consultants; 1995.

22. Leat SJ, Fryer A, Rumney NJ. Outcome of low vision aid provision: The effectiveness of a low vision clinic. Optom Vis Sci. 1994;71(3):199-206. [PMID: 8196946$]$

23. Stelmack JA, Stelmack TR, Fraim M, Warrington J. Clinical uses of the Pepper Visual Skills for Reading Test in low vision rehabilitation. Am J Optom Physiol Opt. 1987; 64(11):829-31. [PMID: 3425678]

24. Goodrich GL, Mehr EB, Darling NC. Parameters in the use of CCTV's and optical aids. Am J Optom Physiol Opt. 1980;57(12):881-92. [PMID: 6164297]

25. Nilsson U. Visual rehabilitation with and without educational training in the use of optical aids and residual vision. A Prospective study of patients with age-related macular degeneration. Clin Vis Sci. 1990;6:3-10.

26. Fridal G, Jansen L, Klindt M. Courses in reading development for partially sighted students. J Vis Impair Blind. 1981; 75(1):4-7.
27. Watson GR, Wright V, De l'Aune WR. The efficacy of comprehension training and reading practice for print readers with macular loss. J Vis Impair Blind. 1992;86(1):37-43.

28. Baldasare J, Watson GR, Whittaker SG, Miller-Schafer H. The development and evaluation of a reading test for low vision individuals with macular loss. J Vis Impair Blind. 1986;80(6):785-89.

29. Stelmack JA, Reda D, Ahlers S, Bainbridge L, McCray J. Reading performance of geriatric patients post exudative maculopathy. J Am Optom Assoc. 1991;62(1):53-57. [PMID: 1813493]

30. Watson GR, Baldasare J, Whittaker SG. The validity and clinical uses of the Pepper Visual Skills for Reading Test. J Vis Impair Blind. 1990;84(3):119-23.

31. Legge GE, Ross JA, Luebker A, LaMay JM. Psychophysics of reading. VIII. The Minnesota Low-Vision Reading Test. Optom Vis Sci. 1989;66(12):843-53. [PMID: 2626251]

32. Nilsson UL, Frennesson C, Nilsson SE. Location and stability of a newly established eccentric retinal locus suitable for reading, achieved through training of patients with a dense central scotoma. Optom Vis Sci. 1998;75(12):873-78. [PMID: 9875992]

33. Nilsson UL, Frennesson C, Nilsson SE. Patients with AMD and a large absolute central scotoma can be trained successfully to use eccentric viewing, as demonstrated in a scanning laser ophthalmoscope. Vision Res. 2003;43(16): 1777-87. [PMID: 12818347]

34. Cummings RW, Rubin GS. Reading speed and saccadic eye movements with an artificial paracentral scotoma [abstract]. Invest Ophthalmol Vis Sci. 1992;33(Suppl):1418.

35. Fine EM. Reading with central scotoma: What can we learn from simulation studies? Vis Impair Res. 1999;1(3): 165-73.

36. Sunness JS, Schuchard RA, Shen N, Rubin GS, Dagnelie G, Haselwood DM. Landmark-driven fundus perimetry using the scanning laser ophthalmoscope. Invest Ophthalmol Vis Sci. 1995;36(9):1863-74. [PMID: 7635660]

37. McMahon TT, Hansen M, Stelmack JA, Oliver P, Viana MA. Saccadic eye movements as a measure of the effect of low vision rehabilitation on reading rate. Optom Vis Sci. 1993;70(6):506-10. [PMID: 8336914]

Submitted for publication July 7, 2005. Accepted in revised form February 27, 2006. 